\title{
Analysis of Excitation Functions from Light Ion Induced Reactions in the EXCLUSIVE INDEX Model
}

J. Ernst, W. Friedland, and H. Stockhorst

Institut für Strahlen- und Kernphysik, Universität Bonn, Nussallee 14-16, D-5300 Bonn 1, Federal Republic of Germany

Received June 5, 1989

Z. Phys. A - Atomic Nuclei 333, 45 (1989)

Reference 30 was incorrectly printed and should have read as follows:

30. Stockhorst, H., Ernst, J.: Proceedings of the International Symposium on Collective Phenomena in Nuclear and Subnuclear Long Range Interactions in Nuclei, Bad Honnef, May 4-7, 1987. David, P. (ed.), p. 336. Singapore, New York, Hong Kong: World Scientific 1988 